\title{
Estimation urban railway demand in Yogyakarta using Bivariate Ordered Probit Model
}

\author{
Wida Yuliar Rezika ${ }^{1, *}$, Sapto Priyanto ${ }^{1}$, Muhammad Zudhy Irawan ${ }^{1}$ \\ ${ }^{1}$ Universitas Gadjah Mada, Depart. of Civil and Environmental Engineering, Yogyakarta, Indonesia
}

\begin{abstract}
The urban railway system is believed to solve transportation problems caused by the high growth of private vehicles and urbanization. This study is going to analyze the potential demand for the urban railway in Yogyakarta, Indonesia based on bivariate ordered probit model. The survey of preference stated with 120 samples conducted in Yogyakarta. The model of train demand is distinguished between public transport users and private vehicle users using seven scenarios. In-train travel time, waiting time, tariff, and ticketing discount for students are four factors considered in the model. The demand model shows that in-train travel time is the most important factor influence for train demand. Meanwhile, the scenario result reveals that respondents except student are willing to pay more to obtain shorter travel time, students who use private vehicle are reluctant to shift into the train, and ticketing discount brings no effect to stimulate them to use the train.
\end{abstract}

\section{Introduction}

High urbanization in developing countries, triggered by the discrepancy of job opportunity between urban and rural area, and followed by significant growth in the number of private vehicles, has caused an increase in urban transportation problem (Vuchic,2007). In solving those problems, implementing an urban railway system becomes an effective solution to mitigate congestion on a regional level (Creemers et al., 2015). The railway system is worthy of the urban transport backbone of its superior features such as high occupancy, environmentally friendly, and energy saving (Profillidis, 2006).

Several major cities in Indonesia are facing rapid growth in urbanization and vehicle ownership, such as Yogyakarta. The Ministry of National Development Planning shows the population growth rate in urban areas is $2.75 \%$ higher than the national average growth which is $1.7 \%$. Moreover, the number of the motorcycle has doubled in the last five years (Bureau of National Statistics, 2014). Regarding to the problems, the Ministry of Transportation arranges regulation to improve the transportation services and solve the transportation problems. It is necessary to provide a urban railway system besides the existing bus rapid transit in Yogyakarta. Then, the master plan of the national railway has

\footnotetext{
* Corresponding author: widayuliar@gmail.com
} 
been decided that Yogyakarta urban railway must be constructed in 2016 and operated in 2020 (Ministry of Transportation and Communication, 2010).

Yogyakarta has a great prospective for urban railway development because of its high-population-density, around 134 persons per hectare (Bureau of Yogyakarta Regional Statistics, 2014). Bus transportation becomes the main public transport in Yogyakarta. Yet, the failure to present the bus arrival time information and the uncertainty of departure time impact to the reluctance to using public transportation. The presence of urban railway service, with segregated tracks, is expected to shift private vehicle users to train users. Figure 1 shows the transportation network and public transport facilities in Yogyakarta.

This study is aimed to estimate the potential demand for Yogyakarta urban railway related to the affecting factors such as fare and ticketing discount, in-train travel time, and waiting time. It also simulate how the changing of these factors influnces the demand in a scenario-based analysis. Bivariate ordered probit model is used because the ability to capture the ordinal response (strongly disagree to strongly agree) compare to the other choice of decision-making models (disagree or agree). Meanwhile, factor analysis is engaged to identify and arrange the service factors which impact the willingness of the train users candidate and then classified it into bivariate ordered model.

Usually, most studies on demand used discrete choice analysis. Those studies have focused on examining the behavior of the decision-making process such as choice of car type (Tanaka et al., 2014; Hackbarth and Madlener, 2013; Ito et al., 2013) and choice of travel mode (Dissanayke and Morikawa, 2005; Habib, 2012; Irawan and Sumi, 2012). Based on the author's knowledge, only few studies use bivariate/multivariate ordered probit model for estimating the potential demand. Most of them are using multinomial logit, multinomial probit and nested multinomial logit. The implementation of ordered probit in this research becomes crucial because the model able to predict the level of certainty as a train user (i.e. strongly won't use; won't use; neither won't use nor will use; will use; and strongly will use).

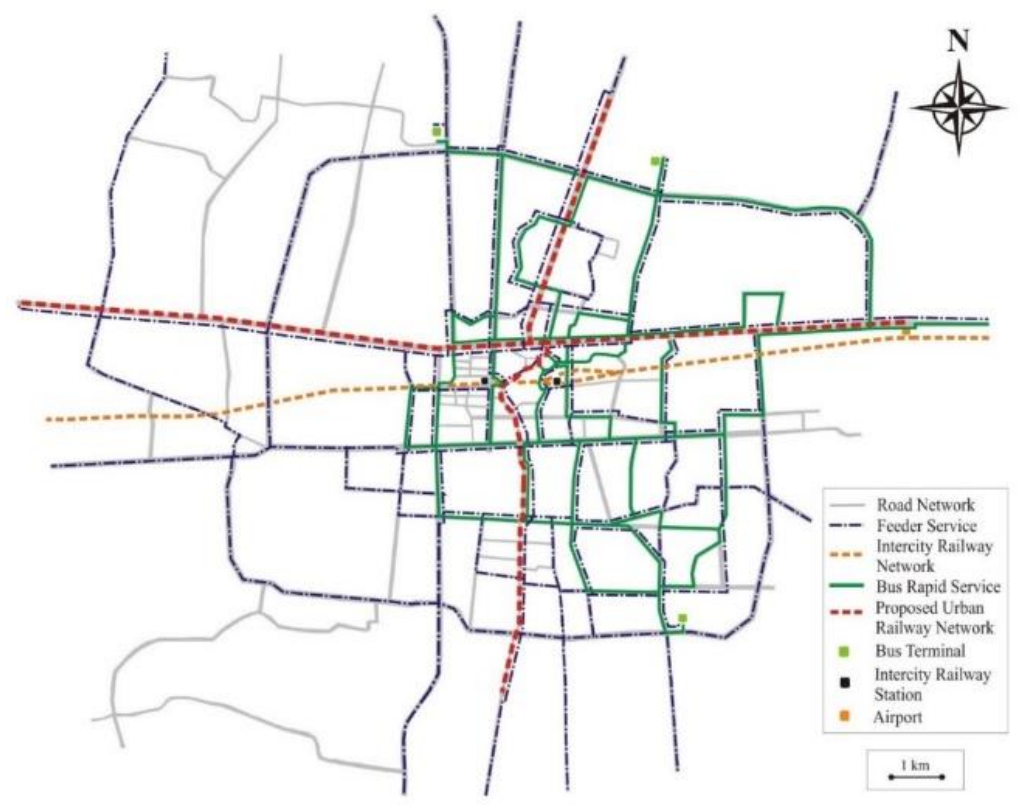

Fig 1. Transportation network and public transport facilities in Yogyakarta 
The rest of this paper is devided into five sections. In the second section, factor analysis is describe as a preliminary survey to obtain a simplification of factors influences the decision of the user to choose the train. In the third section, a bivariate ordered probit model is explained as a research method. The fourth section describes the selection of variable included in the model. Finally, the last two section are the result and conclusion sections. Both of the sections discuss and draw conclusions on how the demand for urban railway can be increased by the implementation of several scenarios regarding the performance of the urban railway.

\section{Bivariate Ordered Probit Model}

The estimation demand of urban railway as a travel mode choice process can be described by the utility function. McFadden (1974) explains the functions consists of two components; the observed utility of the alternative and a random term. The first component consists of specific attributes of the travel mode and user characteristics. The second component is unobserved attributes and characteristics of the utility. The bivariate ordered probit model is derived by defining the ordinal data y for each observation. For instance with two products (Greene and Hensher, 2009):

$$
\begin{array}{ll}
y_{i, 1}=\beta^{\prime}{ }_{1} X_{i, 1}+\varepsilon_{i, 1}, & y_{i, 1}=j \ldots \text { if } \mu_{j-1}<y_{i, 1}<\mu_{j}, j=0, \ldots, J_{1} \\
y_{i, 2}=\beta_{2}^{\prime} X_{i, 2}+\varepsilon_{i, 2}, & y_{i, 2}=j \ldots \text { if } \theta_{j-1}<y_{i, 2}<\theta_{j}, j=0, \ldots, J_{2}
\end{array}
$$

where,

$\mathrm{Y} \quad$ : $\quad$ integer ordering level of certainty as a train user

$\beta \quad$ : estimable parameters

$\mathrm{X}$ : $\quad$ explanatory variables effect to use urban railway

$\mu, \theta: \quad$ estimable threshold parameters that define $\mathrm{y}, \mathrm{j}$ integer ordered certainty levels

$\varepsilon \quad: \quad$ random error terms, assumed to be normally distributed $(N)$ with zero mean and variance of one

The cross-equation correlated error terms are :

$$
\left(\begin{array}{l}
\varepsilon_{i, 1} \\
\varepsilon_{i, 2}
\end{array}\right) \sim N\left[\left(\begin{array}{l}
0 \\
0
\end{array}\right),\left(\begin{array}{ll}
1 & \rho \\
\rho & 1
\end{array}\right)\right]
$$

Where $\rho$ cross-equation correlation coefficient of the error terms.

The bivariate ordered probit model with ordered selection joint probability for $y_{i, 1}=\mathrm{j}$ and $y_{i, 2}=\mathrm{k}$ is defined as follows:

$$
P\left(Y_{i, 1}=j, y_{i, 2}=k \mid X_{i, 1}, X_{i, 2}\right)=\left(\begin{array}{c}
\Phi_{2}\left[\left(\mu_{j}-\beta_{1}^{\prime} X_{i, 1}\right),\left(\theta_{k}-\beta_{2}^{\prime} X_{i, 2}\right), \rho\right] \\
-\Phi_{2}\left[\left(\mu_{j-1}-\beta_{1}^{\prime} X_{i, 1}\right),\left(\theta_{k}-\beta_{2}^{\prime} X_{i, 2}\right), p\right]
\end{array}\right)-\left(\begin{array}{c}
\Phi_{2}\left[\left(\mu_{j}-\beta_{1}^{\prime} X_{i, 1}\right),\left(\theta_{k-1}-\beta_{2}^{\prime} X_{i, 2}\right), p\right] \\
-\Phi_{2}\left[\left(\mu_{j-1}-\beta_{1}^{\prime} X_{i, 1}\right),\left(\theta_{k}-\beta_{2}^{\prime} X_{i, 2}\right), p\right]
\end{array}\right)
$$

where $\Phi$ stands for standard normal cumulative distribution function.

\section{Variable Specification Dependent Variables}

The dependent variable is discrete variable represents the level of certainty as a train user, which can take one of five discrete values, ranging from very unlikely user to very potential user of Yogyakarta urban railway. 


\section{Independent Variables}

Based on the comprehensive review of studies with respect to modal choice by De Witte et al. (2013), independent variables are divided into four factors: (i) socio-demographic, (ii) spatial characteristics, (iii) journey characteristics, and (iv) socio-psychological factors. However, the four factors above can be classified again into two main categories related to modes attributes and travelers' characteristics. There are several studies use mode attributes or traveler characteristics only (e.g. Recker and Golob, 1979; Lerman and BenAkiva, 1976; Irawan and Sumi, 2012). Most of the recent studies use both categories in the analysis. (e.g., Can, 2013; Masiero and Zoltan, 2013; Yarlagadda and Srinivasan, 2008; Hensher and Rose, 2007; Ewing et al., 2004). Related to mode choice decision process, Can (2013) mentions travel time, travel cost, income, demography, private vehicle ownership, comfort, convenience, and safety are commonly used as independent variables.

This research focuses on user preferences for particular attributes of urban railway which are affected their mode choice decision. The independent variables included in our study are in-vehicle travel time, waiting time, travel cost, and ticketing discount for the student. Apparently, major time component of travel time is in-vehicle travel time and waiting time. These two factors have significant contribution on mode choice decision (Arentze and Molin, 2013; Creemers et al., 2012; Wardman, 2004; Murray, 2001). Waiting time of public transport is also crucial factor in determining travel mode, especially for short trip. Walle and Steenberghen (2006) states Dutch travelers feel 2.3 minutes delay on in-vehicle travel time is equal to 1 minute delay on waiting time.

Looking forward to the travel cost factors, several previous studies show travel cost becomes the main factor in determining the public transport demand (Souche, 2010; Arentze, 2013; Creemers et al., 2015). Meanwhile, according to Paulley et al. (2006), fare and ticket discount for student could be an indicator that influences the travelers' decision to use public transport also. For Example, regional public transport in Germany offers fare discount both for children and university students and it shows significant effect for its demand (Buehler and Pucher, 2012).

\section{Survey And Design}

The data of the research are collected from October to December 2014 in Yogyakarta region. The survey is conducted by face to face interview with the respondents. There are 120 respondents compiled the survey. The survey is sectionalized based on several aspects. Section 1 explores information about the respondent characteristics such as age, gender, occupation, and existing travel mode. Section 2 focuses on familiarity with Yogyakarta urban railway system, an introduction to the railway route, location of the stations, and integration with existing public transport and the stated preferences discrete choice experiment. Respondents are also asked about the importance of a wide range of modes attributes, including those used in the choice experiment, in their mode choice decision.

The research uses stated preference survey method to measure traveler's preferences. As mentioned before, the urban railway attributes are described as in-vehicle travel time, waiting time, travel cost, and ticket discount for student. Table 1 shows the attribute levels of discrete choice experiment used in our study. Since the survey focuses on preferences for particular attributes of train, the researcher generates complete fractional factorial design according to independent variables shown in Table 1. By using this method, there are 81 choice sets for the respondents. Those choices cause difficulty for the respondent to answer the questions. In order to solve the problem, we implement an orthogonal planning method (Louveire et al., 2000). It produces 7 choice sets confront to 120 respondents as presented in Table 2. 
Table 1. Attribute levels

\begin{tabular}{|c|c|c|c|}
\hline Variable & Indicator & Level & Remark \\
\hline \multirow{12}{*}{$\begin{array}{l}\text { Independent } \\
\text { Variables }\end{array}$} & \multirow[t]{3}{*}{ Tariff (flat tariff) } & 0 & Rp. 4,000 (0.3 USD) \\
\hline & & 1 & Rp. 5,000 (0.38 USD) \\
\hline & & 2 & Rp. 6,000 (0.45 USD) \\
\hline & \multirow[t]{3}{*}{ In-train travel time } & 0 & More than existing travel time \\
\hline & & 1 & Similar to existing travel time \\
\hline & & 2 & Less than existing travel time \\
\hline & \multirow[t]{3}{*}{ Waiting time } & 0 & 20 minutes \\
\hline & & 1 & 15 minutes \\
\hline & & 2 & 10 minutes \\
\hline & \multirow{3}{*}{$\begin{array}{l}\text { Ticketing discount for } \\
\text { student }\end{array}$} & 0 & $15 \%$ \\
\hline & & 1 & $25 \%$ \\
\hline & & 2 & $50 \%$ \\
\hline \multirow{5}{*}{$\begin{array}{l}\text { Dependent } \\
\text { Variable }\end{array}$} & \multirow[t]{5}{*}{ Response } & 0 & Strongly won't use \\
\hline & & 1 & Won't use \\
\hline & & 2 & Neither won't use nor will use \\
\hline & & 3 & Will use \\
\hline & & 4 & Strongly will use \\
\hline
\end{tabular}

Table 2. Choice sets of questionnaire

\begin{tabular}{|c|c|c|c|c|c|}
\hline Scenario & Tariff & In-Train Travel Time & $\begin{array}{c}\text { Waiting } \\
\text { Time }\end{array}$ & $\begin{array}{l}\text { Fare } \\
\text { Discount * }\end{array}$ & $\begin{array}{l}\text { Response } \\
\text { (5 scales) }\end{array}$ \\
\hline 1 & Rp. 6,000 & Less than existing & $15 \mathrm{~min}$. & $25 \%$ & \\
\hline 2 & Rp. 4,000 & Similar to existing & $20 \mathrm{~min}$. & $15 \%$ & \\
\hline 3 & Rp. 5,000 & Less than existing & $20 \mathrm{~min}$ & $15 \%$ & \\
\hline 4 & Rp. 6,000 & Similar to existing & $10 \mathrm{~min}$. & $50 \%$ & \\
\hline 5 & Rp. 5,000 & Similar to existing & $10 \mathrm{~min}$. & $15 \%$ & \\
\hline 6 & Rp. 5,000 & More than existing & $15 \mathrm{~min}$. & $25 \%$ & \\
\hline 7 & Rp. 4,000 & More than existing & $15 \mathrm{~min}$. & $15 \%$ & \\
\hline
\end{tabular}

\section{Data Description and Estimation Results}

\section{Respondents' Characteristic}

Table 3 shows descriptive statistics on the demographic profile of the respondents. The result model categories of the research are divided into four groups: (i) public transport users except for student, (ii) students as public transport user, (iii) private vehicle users except for student, and (iv) students as private vehicle user. It makes the percentage of respondents within each category is approximately equal to $20.23 \%, 19.3 \%, 30.95 \%$, $29.52 \%$, respectively. The entire collected data can be analyzed supported by the direct interview survey.

\section{Model Results}

The estimated parameters of bivariate ordered probit model are shown in Table 4 and Table 5 , for public transport users and private vehicle users respectively. The estimated parameters are statistically significant at the $5 \%$ level for both public transport and private vehicle users. It means every independent variables influence significantly for the choice decision. Each parameter also has expected sign. Tariff of train has a negative sign, indicated that high fares are disfavored by travelers. However, tariff becomes the most unconcerned about factor by travelers, except students. Other factors have a positive sign, indicated that high speed, short waiting time, and high train fare discount will increase the probability of travelers to use the urban railway service. 
In-train travel time is the most significant factor influencing train choice decision both for bus users and private vehicle users. It can be emphasized that all of the parameters are greater in private vehicle users than those in public transport users, except for the factor of tariff for non-student users. It represents those private vehicle users are more sensitive to train attributes. Even for (non-student) travelers, they are willing to pay more to obtain the better performances of the train.

\section{Simulations}

The main focus of the scenario analysis is on the impacts of modes attributes on the probability of travelers to use train mode. The best scenario can also be achieved by using this simulation. As explained before, there are seven scenarios as seen in Table 2. The simulation result regarding the potential demand in each scenario is displayed in Table 6 and Figure 2. Generally, train demand generated from student-private vehicle users is the lowest compared to the other users. This situation describes the disinterest of students who use private vehicles to shift into using train mode. They believe private vehicle is faster than the train. They also cannot obtain the advantages offered by using the train.

Table 3. Respondents' characteristics

\begin{tabular}{|l|l|l|l|}
\hline Demographic Variables & Category & Frequency & Percentage (\%) \\
\hline Age & $11-20$ years old & 54 & 45.00 \\
\cline { 2 - 4 } & $21-30$ years old & 39 & 32.50 \\
\cline { 2 - 4 } & $31-40$ years old & 20 & 16.67 \\
\cline { 2 - 4 } & Over 40 years old & 7 & 5.83 \\
\hline Gender & Male & 66 & 55.00 \\
\cline { 2 - 4 } & Female & 54 & 45.00 \\
\hline Occupation & Student & 63 & 52.50 \\
\cline { 2 - 4 } & Business sector staff & 22 & 18.33 \\
\cline { 2 - 4 } & State sector staff & 26 & 21.67 \\
\cline { 2 - 4 } & Other sector staff & 9 & 7.50 \\
\hline Travel mode & Public transport & 47 & 39.17 \\
\cline { 2 - 4 } & Motorcycle & 49 & 40.83 \\
\cline { 2 - 4 } & Motorcycle (escorted) & 7 & 5.83 \\
\cline { 2 - 4 } & Car & 11 & 9.17 \\
\cline { 2 - 4 } & Car (escorted) & 6 & 5.00 \\
\hline
\end{tabular}

Table 4. Parameter estimates for public transport users

\begin{tabular}{|c|c|c|c|c|}
\hline \multirow{2}{*}{ Variable } & \multicolumn{2}{|l|}{ Student } & \multicolumn{2}{|c|}{ Non-Student } \\
\hline & Parameter & Std. error & Parameter & Std. error \\
\hline Constant & $v^{\prime}$ & 0.231 & -0.654 & 0.205 \\
\hline Tariff & -2.138 & 0.419 & -0.905 & 0.198 \\
\hline In-train travel time & 2.46 & 0.292 & 1.901 & 0.186 \\
\hline Ticketing discount for student & 1.365 & 0.29 & - & - \\
\hline Waiting time & 0.922 & 0.192 & 1.201 & 0.189 \\
\hline$\mu_{1}$ & 0.102 & & 0.851 & \\
\hline$\mu_{2}$ & 0.505 & & 0.967 & \\
\hline$\mu_{3}$ & 2.169 & & 1.818 & \\
\hline
\end{tabular}


Table 5. Parameter estimates for private vehicle users

\begin{tabular}{|l|l|l|l|l|}
\hline \multirow{2}{*}{ Variable } & Student & Non-Student & \\
\cline { 2 - 5 } & Parameter & Std. error & Parameter & Std. error \\
\hline Constant & -0.942 & 0.242 & -0.729 & 0.202 \\
\hline Tariff & -4.200 & 0.440 & -0.693 & 0.186 \\
\hline Ticketrain travel time & 4.398 & 0.308 & 2.125 & 0.184 \\
\hline Waiting time & 2.736 & 0.314 & - & - \\
\hline$\mu_{1}$ & 1.766 & 0.202 & 1.280 & 0.176 \\
\hline$\mu_{2}$ & 2.183 & & 0.927 & \\
\hline$\mu_{3}$ & 3.221 & & 1.428 & \\
\hline
\end{tabular}

Scenario 1 results are the highest mode shifting (in average) by 51.59\%. Scenario 1 also produces the highest demand for train service for students who use the bus and non-student private vehicle users. In scenario 2 , the probability of using train mode is significantly decreased compared to scenario 1 for bus users and private vehicle users. It occurs because travel time (in-vehicle and waiting time) in this scenario is longer than travel time in scenario 1, although it offers very much cheaper fare. Shorter in-vehicle travel time, yet followed by an increased tariff, is able to increase the demand for train mode as shown in scenario 3. Therefore, it can be remarked that travel time is considered more than the cost. According to the fourth scenario, the scenario that offers the cheapest fare for students and highest ticket discount shows an insignificant impact on train demand. Yet, the result of highest demand is generated from student private vehicle users. Then, the scenario 5 gives the highest train demand produced from non-student bus users. Similar travel time to current travel mode yet offering shorter waiting time is indicated attracting high demand for urban railway. It means when train speed is unable to pass other vehicles' speed, especially private vehicles (i.e. motorcycles) and creates shorter waiting time; it can be alternative way to increase the train demand.

The scenario 6 is the worst scenario. The poor demand for train modes produced is more influenced by in-vehicle travel time rather than other factors. It can be understood because in-vehicle travel time offered in the sixth scenario is much longer than the 5 scenarios before. The impact of scenario 6, an unexpected demand occurs in the seventh scenario. Reducing tariff and maintaining other variables have no significant impact on the increase of train service demand in this scenario. Moreover, the similar number is shown in train service demand generated from students who use private vehicles.

Table 6. Demand for urban railway service in the scenarios (in \%)

\begin{tabular}{|l|l|l|l|l|}
\hline \multirow{2}{*}{ Scenario } & \multicolumn{2}{|l|}{ PT Users } & \multicolumn{2}{l|}{ Private Vehicle Users } \\
\cline { 2 - 5 } & Non-Student & Student & Non-Student & Student \\
\hline 1 & 76.42 & 52.79 & 74.86 & 2.28 \\
\hline 2 & 28.43 & 34.09 & 8.85 & 0.62 \\
\hline 3 & 66.28 & 46.81 & 53.19 & 1.07 \\
\hline 4 & 50.80 & 45.62 & 42.86 & 2.94 \\
\hline 5 & 82.38 & 24.20 & 69.85 & 0.08 \\
\hline 6 & 1.46 & 0.33 & 0.19 & 0.01 \\
\hline 7 & 10.20 & 2.62 & 1.39 & 0.01 \\
\hline
\end{tabular}




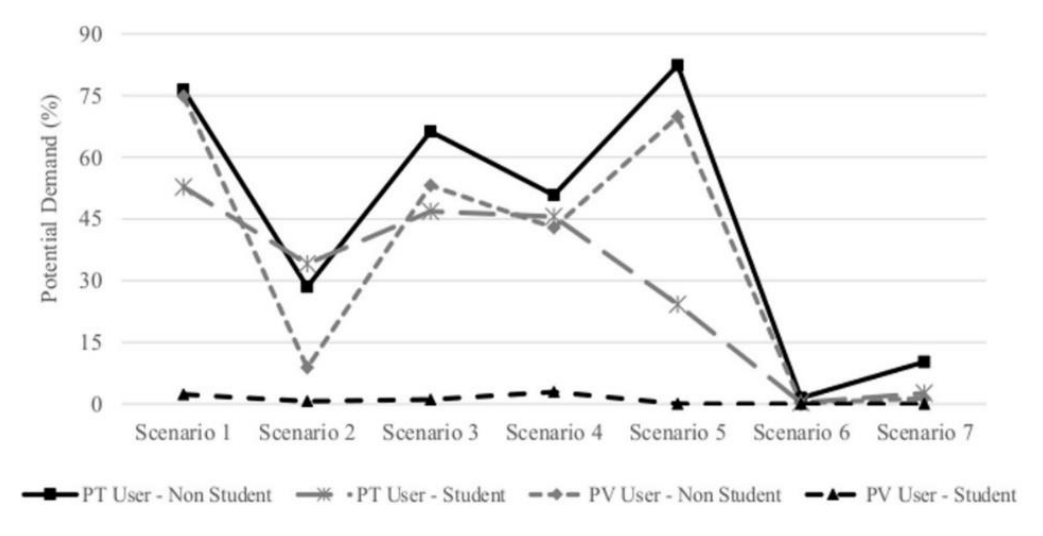

Fig. 1. Simulated potential demand for Yogyakarta urban railway

\section{Conclusions}

The research studies the potential demand for Yogyakarta urban railway service by using bivariate ordered probit model. The result of the research shows students who use private vehicles are very reluctant toward the train. It could be great barrier in terms of shifting to train use. However, the railway service as an alternative mode can be accepted for private vehicle users for work. In-train travel time and waiting time become the major factors influenced Yogyakarta urban railway demand for bus users and private vehicle users. Yet, ticket and fare discount for students have no significant outcome for train service demand. Travelers except the students are willing to pay more to obtain an optimal travel time. From the 7 scenarios simulated, scenario 1 is the best scenario in generating demand for train mode. However, scenario 6 and scenario 7 should not be considered as policy making options, since both of the scenarios produce poor demand for urban railway.

\section{References}

1. Arentze, T. "Personalized travel information systems: a Bayesian method to learn users' personal preferences in multimodal transport networks." IEEE Transactions on Intelligent Transportation System, Vol. 14, No. 4, pp. 1957-1966, DOI: 10.1109/TITS.2013.2270358. (2013).

2. Arentze, T., Molin, E.J.E. "Travelers' preferences in multimodal networks: design and results of a comprehensive series of choice experiments." Transportation Research Part $A$, Vol. 58, pp. 15-28, DOI: 10.1016/j.tra.2013.10.005. (2013).

3. Buehler, R., and Pucher, J. "Demand for public transport in Germany and the USA: an analysis of rider characteristics." Transport Reviews, Vol. 32, No. 5, pp. 541-567, DOI: 10.1080/01441647.2012.707695. (2012).

4. Bureau of Yogyakarta Regional Statistics (2014). Yogyakarta Statistic Annual Report, Yogyakarta, Indonesia.

5. Can, V.V. "Estimation of travel mode choice for domestic tourists to Nha Trang using the multinomial probit model." Transportation Research Part A, Vol. 49, pp. 149-159, DOI: 10.1016/j.tra.2013.01.025. (2013). 